\title{
Continuous subcutaneous insulin infusion vs multiple daily injections in pregnant women with type 1 diabetes mellitus: a systematic review and meta-analysis of randomised controlled trials and observational studies
}

\author{
Przemyslaw M Rys ${ }^{1, *}$, Agnieszka H Ludwig-Slomczynska², *, Katarzyna Cyganek ${ }^{3}$ and \\ Maciej T Malecki ${ }^{3,4}$ \\ ${ }^{1}$ HTA Consulting, Krakow, Poland, ${ }^{2}$ Center for Medical Genomics OMICRON Jagiellonian University Medical College, \\ Krakow, Poland, ${ }^{3}$ University Hospital, Krakow, Poland, and ${ }^{4}$ Department of Metabolic Diseases, Jagiellonian \\ University Medical College, Krakow, Poland
}

Correspondence should be addressed to M T Malecki Email

malecki_malecki@yahoo.com or maciej.malecki@uj.edu.pl

\begin{abstract}
Background: Randomised controlled trials (RCTs) have shown an advantage of continuous subcutaneous insulin infusion (CSII) over multiple daily injections (MDI) in the general type 1 diabetes mellitus (T1DM) population. RCT data on T1DM management in pregnancy remain limited.

Objective: We performed a systematic review of both RCTs and non-RCTs evaluating CSII vs MDI in T1DM-complicated pregnancy.

Study design: Electronic databases were searched for studies comparing CSII with MDI in T1DM-complicated pregnancy.

Methods: A meta-analysis provided point estimates with $95 \%$ confidence intervals (Cl). Continuous outcomes were reported as weighted mean differences (WMD) or standardised mean differences (SMD), and dichotomous data as relative risk $(\mathrm{RR})$.

Results: The search identified 47 studies, including 43 non-RCTs, reporting on 7824 pregnancies. The meta-analysis showed a lower HbA1c level with CSII vs MDI in the first trimester (WMD: $-0.45 \% ; 95 \% \mathrm{Cl}:-0.62,-0.27$ ). This difference decreased in subsequent trimesters. Compared to MDI, therapy with CSII resulted in higher gestational weight gain (GWG) (WMD: $1.02 \mathrm{~kg} ; 95 \% \mathrm{Cl}: 0.41,1.62)$, and lower daily insulin dose requirements in the first (SMD: $-0.46 ; 95 \% \mathrm{Cl}:-0.68,-0.24)$ and subsequent trimesters. Moreover, infants from the CSII group were more likely to be large for gestational age (LGA) (RR: 1.16; $95 \% \mathrm{Cl}: 1.07,1.24)$ and less likely to be small for gestational age (SGA) (RR: 0.66 ; $95 \% \mathrm{Cl}: 0.45 ; 0.97)$.

Conclusions: In T1DM-complicated pregnancy, CSII compared to MDI therapy resulted in better first trimester glycaemic control; this difference decreased in subsequent trimesters. CSII therapy was associated with lower insulin requirements, higher GWG and altered risk for infants being LGA and SGA.




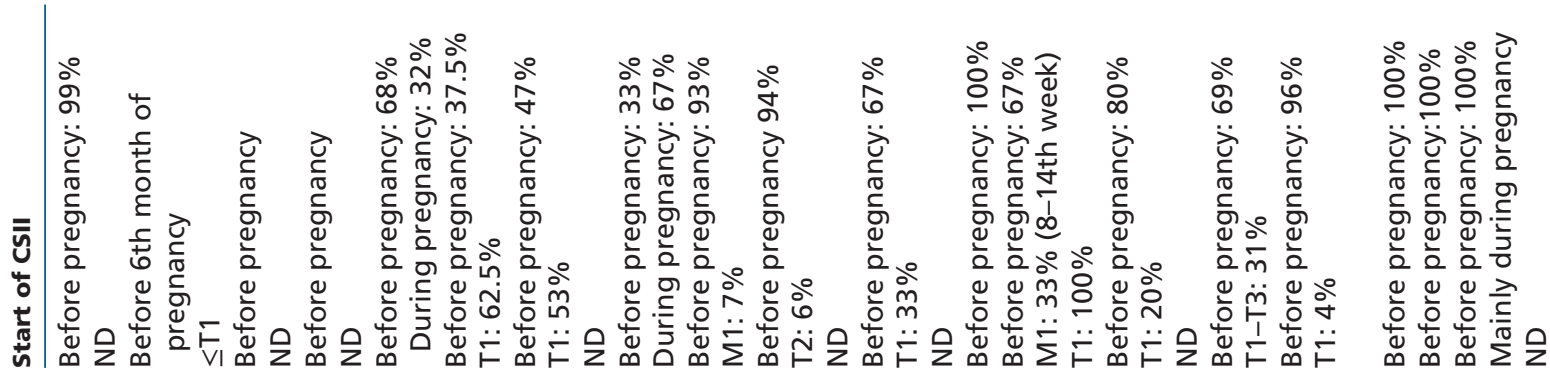

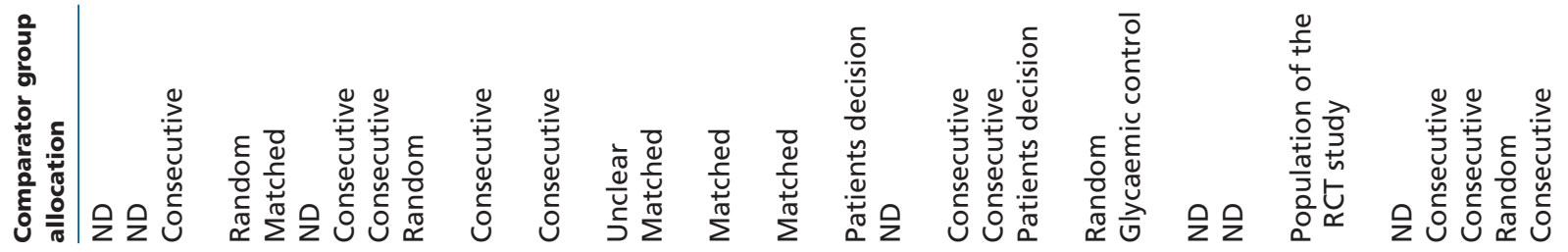

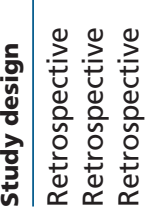

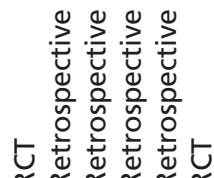

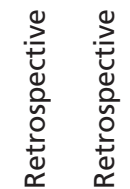

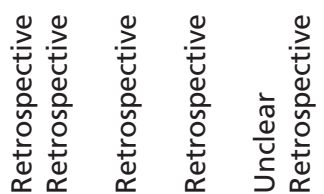

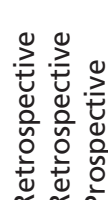

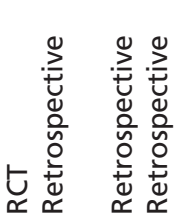

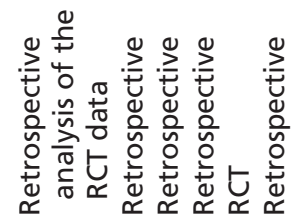

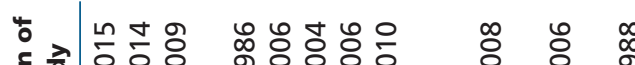

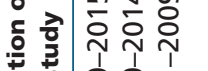

ㅇำ

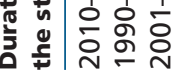

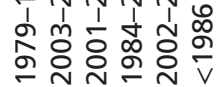

ì

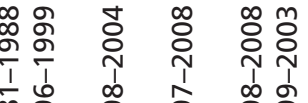

은

๓̊ ঠ



స $\quad$ กั

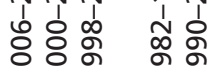

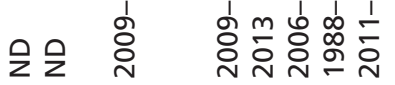

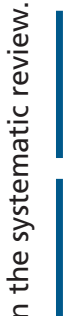

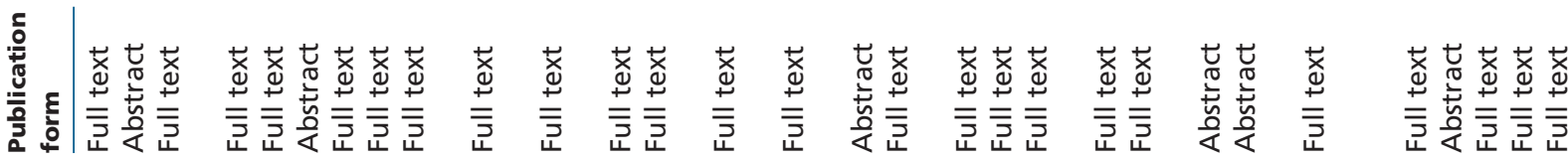



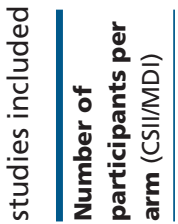

$\stackrel{\infty}{\stackrel{\infty}{\sim}} \widehat{\infty}$

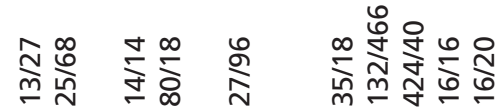

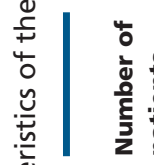

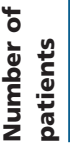

ক্ণ

$\stackrel{\infty}{\infty} \stackrel{\infty}{\infty} \stackrel{m}{\infty}$

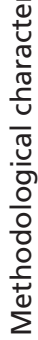

$\left(\frac{10}{20}\right.$

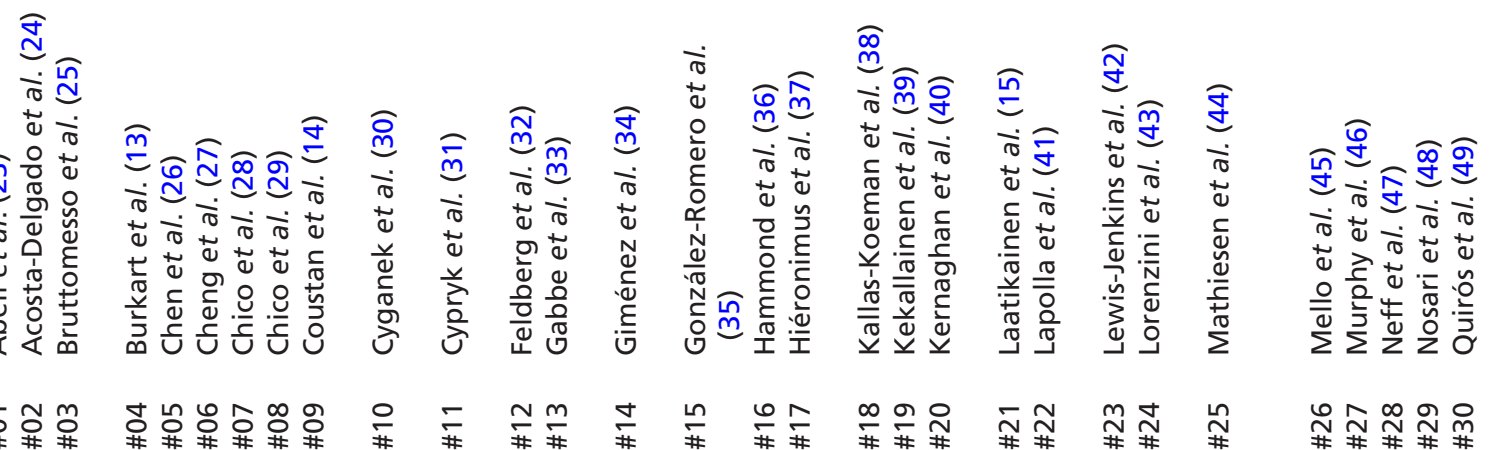




\section{Introduction}

Given that the onset of type 1 diabetes mellitus (T1DM) usually occurs early in life, many women of reproductive age worldwide are affected $(1,2,3,4)$. Recent literature has remarked that the incidence of T1DM is rising (5). Women with pregestational T1DM have an increased risk of adverse clinical outcomes, including spontaneous abortions, foetal malformations, macrosomia, stillbirths, preeclampsia, hydramnios, operative delivery in mothers, and progression of chronic diabetic complications (6). The risk of congenital abnormalities is as high as $25 \%$ in women with T1DM who have a $\mathrm{HbA}_{1 \mathrm{c}}$ level above $10 \%$, and remains higher than the risk in the general population, affecting even pregnant patients with moderate hyperglycaemia (7). Fortunately, effective medical care provided to women with pregestational T1DM can foster enhanced glycaemic control and reduce the risk of these complications $(8,9,10)$.

New therapeutic and monitoring tools for glycaemic control have become commonly available in recent decades. Currently, two modes of insulin delivery for T1DM patients are widely used. The first is based on multiple daily injections (MDI), which involves several shots of short-acting prandial insulin, along with 1-2 doses of a long-acting basal preparation. The second route is continuous subcutaneous insulin infusion (CSII), which provides a constant supply of insulin via a personal pump with superimposed meal-related boluses (11). In the general T1DM population, it has been shown that when compared with MDI, CSII was associated with a slightly lower $\mathrm{HbA}_{1 \mathrm{c}}$ level and a smaller risk of severe hypoglycaemia (12). Until now, however, only a few small randomised control trials (RCTs) including T1DM pregnant women have been performed, and no firm understanding as to whether either of these treatment methods is advantageous in this particular patient population exists $(13,14,15)$. Two comprehensive reviews comparing CSII with MDI in pregnancy complicated by T1DM were in fact recently published. Neither, however, revealed any conclusive results for both glycaemic control and clinical maternal and foetal outcomes, as they were restricted only to RCTs, which were few and underpowered $(16,17)$.

The aim of our study was to perform a systematic review and meta-analysis based on both randomised and non-randomised data comparing the two methods of insulin therapy in pregnant women with T1DM, with respect to glycaemic control, particularly the HbA1c level, as well as important maternal and foetal endpoints. 


\section{Subjects and methods}

\section{Eligibility criteria for meta-analysis}

Studies were considered relevant for this systematic review if they directly compared CSII with MDI in pregnant women with pregestational T1DM. No restriction was made with respect to the type of insulin used (regular vs analogue), however, studies reporting data on animal insulin or involving less than 10 pregnancies in any group were excluded.

Randomised and observational studies were included if they presented outcomes on glycaemic control or maternal and foetal outcomes, regardless of the type of publication (i.e. full-text paper or conference abstract). Overall we consider 4 glycaemic control parameters (HbA1c level, insulin dose, diabetic ketoacidosis (DKA), severe hypoglycaemic episodes), 3 maternal outcomes (gestational weight gain (GWG), gestational hypertension and preeclampsia) as well as 11 foetal and neonatal endpoints (perinatal death, congenital abnormalities, preterm delivery, macrosomia, delivery of large-forgestational-age (LGA) infants, delivery of small-forgestational-age (SGA) infants, hypoglycaemic events, hyperbilirubinemia, shoulder dystocia, respiratory complications, and intensive care unit admission).

\section{Information sources and search strategy}

Major medical databases were searched until November 2017, including MEDLINE, EMBASE and CENTRAL, with a high-sensitivity search strategy based on key words referring to the population ('type 1 diabetes mellitus', 'insulindependent diabetes mellitus', 'pregestational', 'maternal', 'gestational') and intervention ('continuous subcutaneous insulin infusion', 'insulin pump', 'pump therapy'). To identify recently published studies, abstracts presented at major conferences on diabetes (ADA, American Diabetes Association; EASD, European Association for the Study of Diabetes) were screened, along with clinical trial registries. We also searched the reference lists of included articles and systematic reviews. Two authors independently selected studies for potential inclusion based on title and abstract screening, followed by full-text evaluation, if available. Any disagreements were resolved through discussion.

\section{Data extraction and quality assessment}

Data were extracted from the identified studies onto a structured data form by the main author. Its precision was verified independently by an external reviewer not engaged in the systematic review. All included studies underwent a quality assessment. For RCTs, criteria outlined in the Cochrane Handbook for Systematic Reviews of Interventions were used; in particular, each study was analysed in terms of presence of selection, performance, detection, attrition and reporting biases. Additionally, quality assessment based on the Jadad scale was performed (18). For non-RCT studies, the NewcastleOttawa Scale (NOS) for quality assessment was used, which takes into account sampling, differences between studied groups and method of outcome assessment (19).

\section{Statistical analysis}

Dichotomous outcomes estimates were presented as relative risks (RR), while continuous endpoints were reported as weighted mean differences (WMD) or standardised mean differences (SMD). If heterogeneity between studies existed, data were pooled in meta-analyses using the DerSimonian \& Laird method, regardless of type of outcomes; otherwise, the Mantel-Haenszel test for dichotomous outcomes was applied and the inverse variance method was used for continuous endpoints. Heterogeneity between studies was tested using the Cochrane $Q$ test or $\mathrm{I}^{2}$ statistics and judged relevant when $P<0.1$ or $\mathrm{I}^{2}>50 \%$. To explain the source of heterogeneity, a sensitivity analysis was also performed considering the following modifiers: study design (randomised vs observational), type of publication (conference abstract vs full-text article), time of CSII initiation (before or during pregnancy), preconception care (yes or no), type of prandial insulin (human regular insulin vs insulin analogues). The chi-square test for interaction was used to evaluate if the observed effect was consistent between subgroups. Risk of publication bias was evaluated by the Egger and Begg-Mazumdar tests (20). If a risk of publication bias was found, the trim and fill method was used to adjust the funnel symmetry $(21,22)$.

\section{Results}

\section{Study selection}

In total, the search of major medical databases yielded 1327 papers, of which 1140 unique records remained after eliminating duplicates. Search of other sources, such as EASD or ADA conference abstracts, led to the inclusion of 1368 records. Five additional articles were found from the reference lists. Based on title and the abstract screening, 134 records proceeded for further full-text analysis, if 
available. A total of 69 papers were excluded due to an inadequate population, intervention, method, cohort size, outcome or comparator. Finally, 47 studies (65 records) met the eligibility criteria (Supplementary Fig. 1, see section on supplementary data given at the end of this article), including 29 full-text papers and 18 conference abstracts. Some studies were published in more than one paper, increasing the number of records in relation to number of studies. In most cases, they were initially published as a conference abstract and then as a full-text article.

\section{Study characteristics}

The 47 studies included in this analysis were conducted in 18 countries, with the highest number being performed in the United States of America (8), Spain (7), Great Britain (6), Italy (5), and Poland (3). Among the included studies, there were only 4 RCTs, all of them of a very low quality, with a high risk of systematic bias. They were also all conducted before the year 1990, so the studied standard of care and available diagnostic and therapeutic options for T1DM does not reflect current clinical practice. The remaining 43 studies were observational: 39 were retrospective, 2 were prospective and no information about the study design was given for the remainder.

In 21 studies, no information about the allocation was given; 6 reports matched patients in the studied groups, while 12 included all eligible patients identified during a study period. Allocation to the MDI or CSII group based on glycaemic control was applied in 2 studies, while in 3 others, the choice of therapy was left to the patient (Table 1).

Quality assessment with the NOS showed a wide variety between the observational studies, ranging from 4 to 9 points, which stemmed mainly from the publication form. Most full-text papers received between 6 and 9 points (median 7), while the median for conference abstracts was only 5 (range: 4-6 points).

Of the 47 studies that met the inclusion criteria, 7824 pregnancies were reported, including 2651 women on CSII and 5030 on MDI. In two papers (143 patients), no information about group sizes was given. Overall, both arms were well-balanced in terms of age, microangiopathy and hypertension, while some differences regarding T1DM duration, baseline glycaemic control and preconception care existed. Means or medians of disease duration were reported in 31 studies. In the CSII group, they ranged from 8.2 to 22 years, compared to a range of 6.9 to 18.7 years in the MDI group. In 15 out of 31 studies in which the duration of T1DM was presented, the CSII group was characterised by a longer time course of disease, while no differences were seen in another 15 studies; in only 1 report did the CSII group have a shorter disease duration on average.

Prepregnancy HbA1c levels were reported in 24 studies; however, only 21 of them provided the difference between the groups. A total of 8 papers reported lower prepregnancy $\mathrm{HbA}_{1 \mathrm{c}}$ levels in the CSII group, 1 reported the opposite and no differences were reported in the remaining, although non-significantly lower values were seen for CSII. Preconception care was reported in 19 papers; however, comparison between the studied groups was possible in only 16 papers. In 12 of these 16 papers, the percentage of those who received preconception care was significantly higher in the CSII group; the difference was not significant in the remaining 4 papers, although a tendency towards CSII could be seen in 3 of them.

Different insulin types were used in the included papers. The CSII group used regular human insulin (RHI) or rapid-acting insulin analogues (RAA). Those in the MDI group performed at least 4 injections, 3 of which were postprandial (RHI or RAA), and 1 or 2 of which were basal insulin (mostly NPH). Information about the glucose monitoring method was reported in 23 studies. In all of them, self-monitoring of blood glucose (SMBG) was used, and in 3 studies, SMBG was used together with continuous glucose monitoring (CGM). Nine studies only included women who started CSII before pregnancy, and 2 studies only included women who initiated pump therapy during the first trimester. In 15 papers, the population encompassed women who initiated CSII either before pregnancy or during the first trimester, while no information about CSII initiation was presented in 23 studies (Table 2).

\section{Synthesis of results}

$\mathrm{HbA}_{1 c}$ level

A meta-analysis of the 24 trials (3104 pregnancies) reporting on the first trimester HbA1c level revealed almost $0.5 \%$ lower level in the CSII group than in the MDI group (WMD: -0.45 95\% CI: $-0.62,-0.27$; Fig. 1); however, significant heterogeneity existed between the studies $\left(I^{2}=78 \%\right)$. The subgroup analysis showed that the magnitude of the effect size when compared to the MDI group was higher in women who started pump therapy before pregnancy (WMD $-0.60 \%$; 95\%CI $-0.97,-0.24$; Supplementary Fig. 21) than in those who did it during the first trimester (WMD -0.35\%; 95\%CI -0.92, 0.22; Supplementary Fig. 22). The HbA1c level in the second trimester was reported in 18 studies, encompassing 1902 pregnancies. The CSII group showed lower $\mathrm{HbA}_{1 \mathrm{c}}$ level, with WMD in relation to the comparator group 


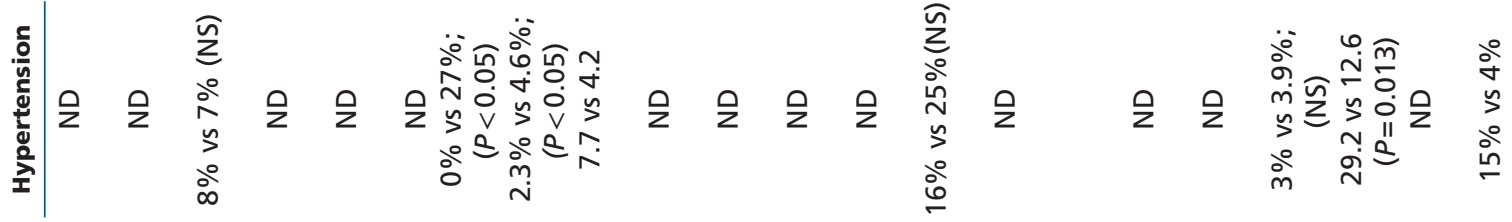





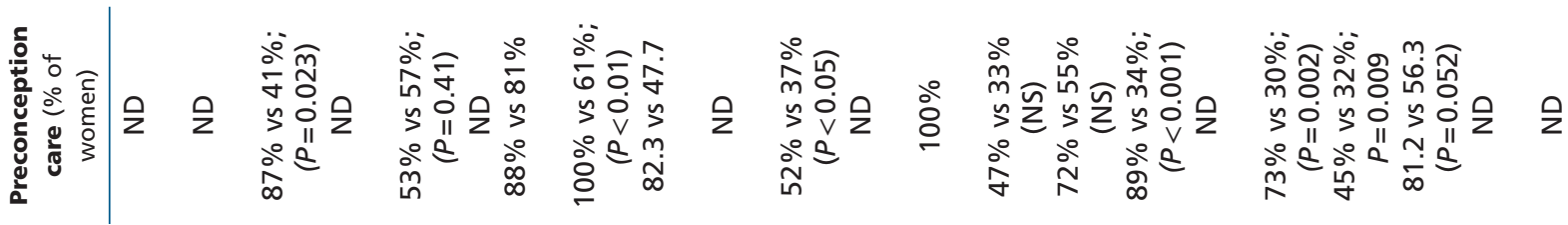



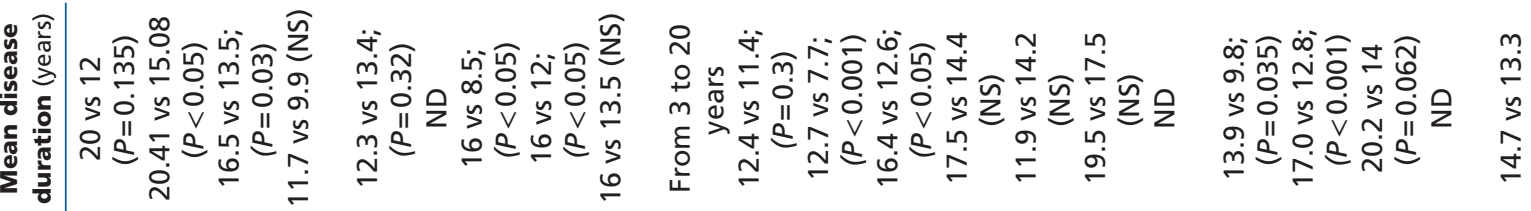

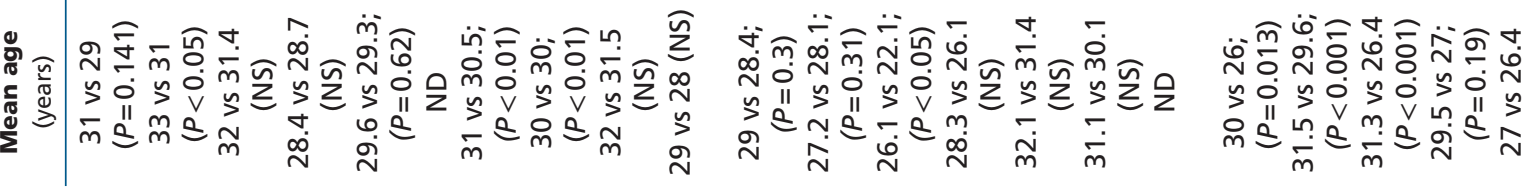



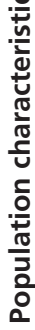

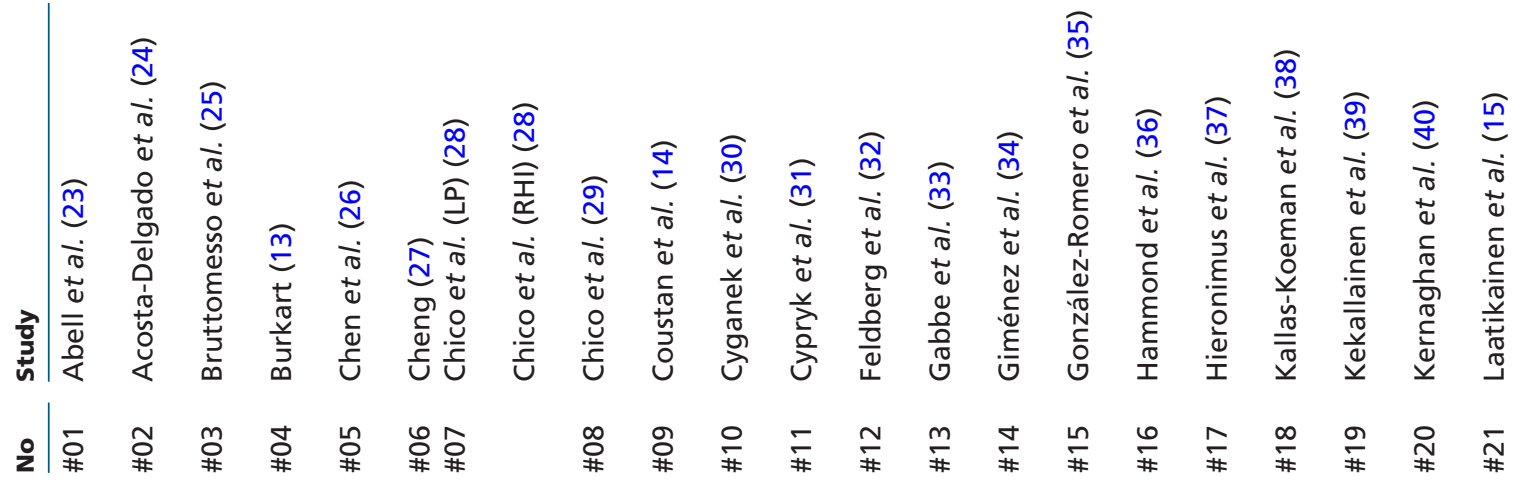


(1)

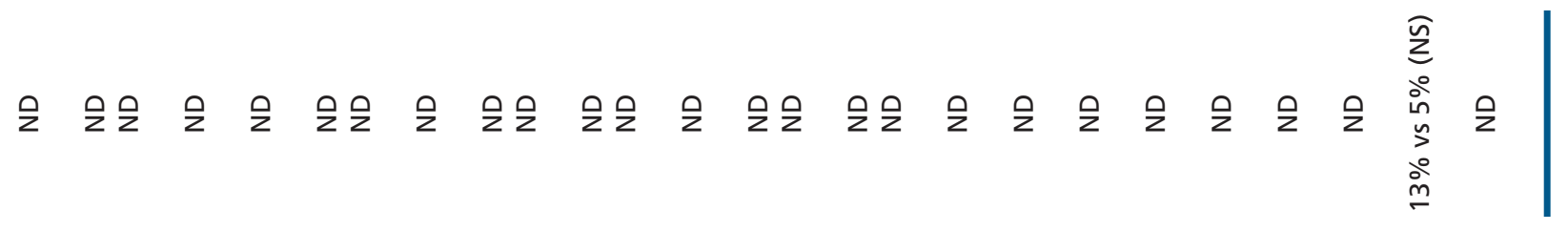

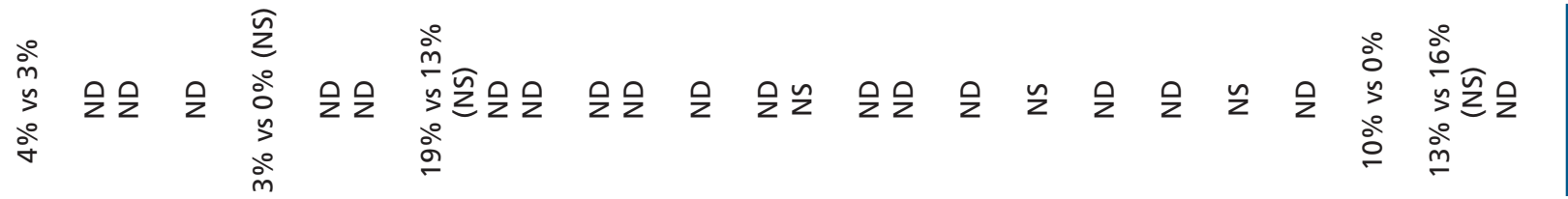

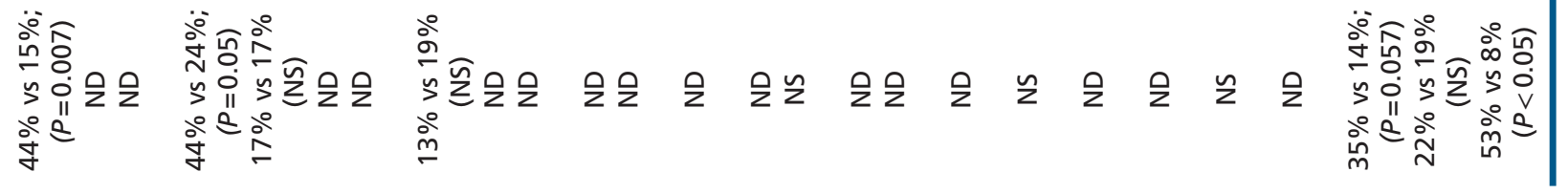

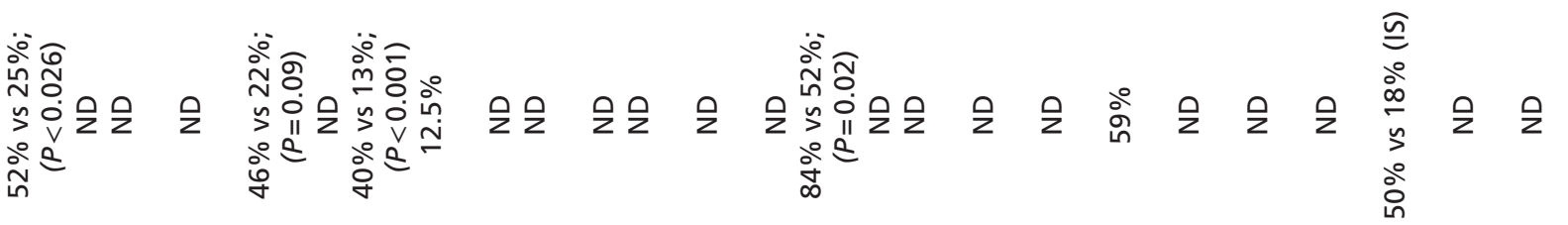

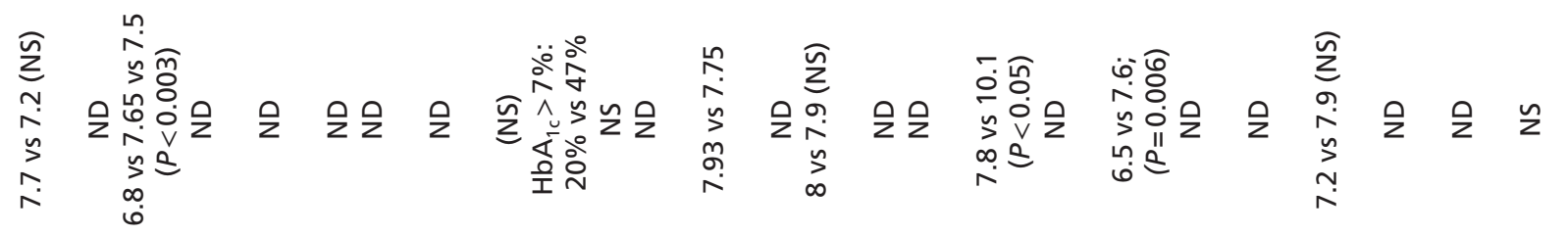

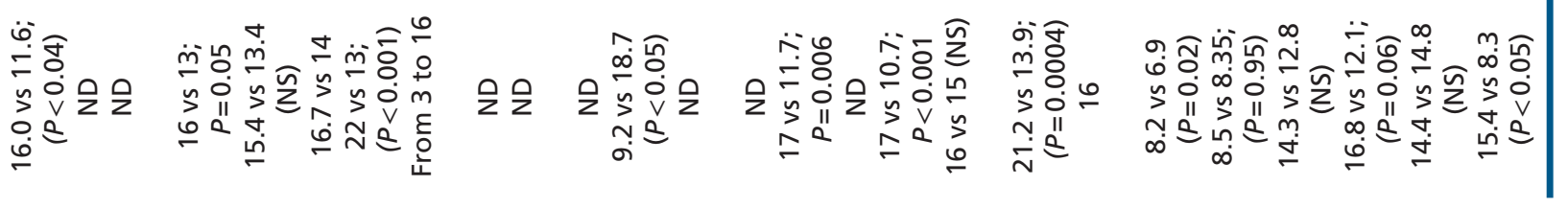

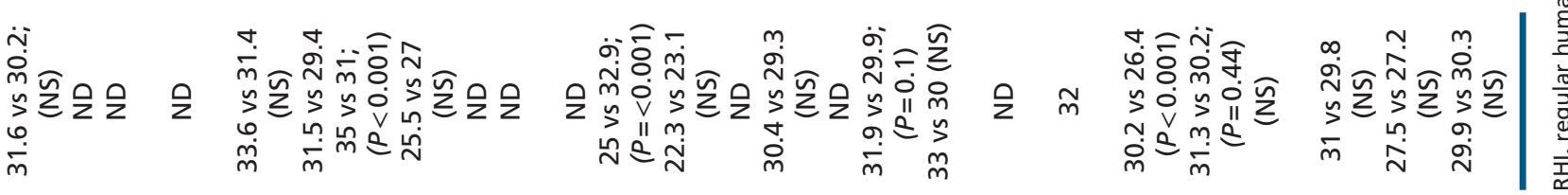

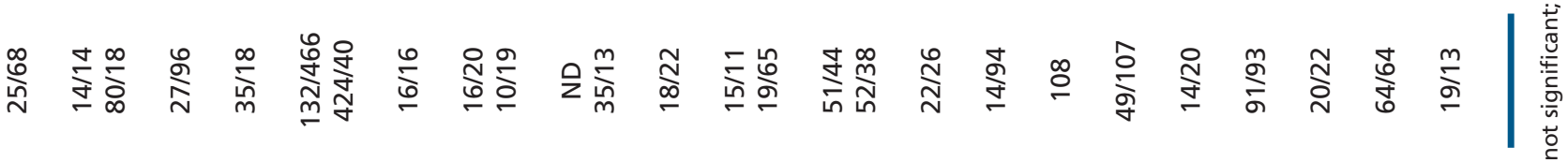




reaching $-0.25 \%$ (95\%CI $-0.38,-0.12$; Fig. 2). Twentythree papers, encompassing 2696 pregnancies, reported on the HbA1c level in the third trimester. In the CSII arm, the HbA1c level was lower than that in the MDI group (Fig. 3); however, the difference between groups was not significant (WMD -0.09\%; 95\%CI -0.20, 0.02). Similar to the analysis of the first trimester, significant heterogeneity between studies was also observed in the second $\left(\mathrm{I}^{2}=59 \%\right)$ and third $\left(\mathrm{I}^{2}=64 \%\right)$ trimester. The cause of this heterogeneity was not identified.

\section{Episodes of severe hypoglycaemia}

Data regarding episodes of severe hypoglycaemia during pregnancy were available in 18 studies and included 3431 pregnancies (Supplementary Fig. 2). No difference was found between the CSII and MDI groups with respect to the percentage of patients suffering from severe hypoglycaemia (RR $0.85,95 \% \mathrm{CI} 0.67,1.07)$. The obtained results were very homogeneous $\left(\mathrm{I}^{2}=0 \%\right)$.

\section{Diabetic ketoacidosis}

The meta-analysis of 17 studies involving 2087 pregnancies demonstrated that the percentage of patients with DKA was low and comparable between arms (RR 1.27, 95\%CI $0.72,2.24)$. No significant heterogeneity was observed in this analysis (Supplementary Fig. 3).

Insulin dose Overall, 15 studies provided data regarding insulin dose in the first trimester. In 8 papers, the total daily dose was available, while the remaining 7 reported insulin dose per body weight (IU/kg). Pooled results of all studies (regardless of the type of data) showed lower insulin requirements in women with T1DM on CSII therapy than in those on MDI therapy (SMD -0.46; 95\%CI -0.68, -0.24) (Supplementary Fig. 4). Second trimester insulin dose was available in 6 studies, 2 of which reported total daily dose and 4 reported total insulin dose per body weight. The meta-analysis of all studies showed a lower insulin requirement in the CSII group (SMD $-0.49 ; 95 \%$ CI -0.69 , -0.28) (Supplementary Fig. 5). Thirteen studies reported on the mean daily insulin dose in the third trimester, of which 8 presented data regarding total insulin dose per body weight, while the remaining 5 presented the total daily insulin dose per patient. The meta-analysis of the 13 papers (Supplementary Fig. 6) showed lower insulin requirements in the CSII group (SMD -0.39; 95\%CI $-0.65,-0.13)$.

\section{Maternal outcomes}

Pooled results revealed no significant differences between CSII and MDI therapy with respect to gestational hypertension (11 studies; RR 0.91; 95\%CI 0.70, 1.18; Supplementary Fig. 7), as well as preeclampsia (16 studies, RR 1.06; 95\%CI 0.69, 1.61; Supplementary Fig. 8). Information regarding absolute GWG (in kilograms) was published in 12 studies, encompassing 1364 pregnancies. Meta-analysis of these 12 studies did not show a difference between CSII and MDI therapy (WMD $=0.6195 \% \mathrm{CI}-0.19$, 1.42 ), although high heterogeneity of the studies was observed $\left(\mathrm{I}^{2}=46 \%\right)$, likely resulting from data published by a Spanish group (35) that suggested lower GWG in the CSII arm (mean difference $-2.0 \mathrm{~kg} 95 \% \mathrm{CI}-3.70,-0.30$ ), while most other papers reported the reverse trend. When the Spanish paper was excluded from the meta-analysis, the cumulative results of the 11 other papers showed that GWG was approximately $1.0 \mathrm{~kg}$ higher in the CSII group than in the MDI group (WMD $1.02 \mathrm{~kg}$; 95\%CI 0.41, 1.62) (Fig. 4). This difference was significant and without between-study heterogeneity $\left(\mathrm{I}^{2}=0 \%\right)$.

\section{Foetal and neonatal outcomes}

A meta-analysis of 14 studies revealed significantly higher risk of spontaneous abortion in women using CSII than in those on MDI (RR 1.79; 95\%CI 1.51, 2.12) without statistical heterogeneity (Supplementary Fig. 9). Other foetal complications, including perinatal death, congenital anomalies and preterm delivery, were reported in 19, 28 and 26 studies, respectively, and none of them revealed significant differences between CSII and MDI therapy (Supplementary Figs 10, 11 and 12). Pooled results of all studies meeting inclusion criteria showed no significant differences between CSII and MDI therapy with respect to perinatal deaths (RR 0.83 ; 95\%CI $0.55,1.25$ ), congenital defects (RR 1.14; 95\%CI 0.92, 1.41) and preterm delivery (RR 1.07; 95\%CI 0.97, 1.17).

The pooled results of 27 homogenous studies $\left(\mathrm{I}^{2}=13 \%\right)$ revealed that the percentage of LGA neonates, mainly defined as birth weight $\geq 90 \%$ percentile, was higher in the CSII group when compared to the MDI group (RR 1.16; 95\%CI 1.08, 1.25; Fig. 5). Macrosomia, in most papers defined as birth weight $\geq 4000 \mathrm{~g}$, was also more prevalent in the CSII group than the MDI group (19\% vs $23 \%$ ), but this difference did not reach statistical significance (RR 1.13; 95\%CI 0.93, 1.38; Supplementary Fig. 13), and may be at least partially explained by a high degree of heterogeneity $\left(\mathrm{I}^{2}=55 \%\right)$. However, the cumulative results of 2 studies 


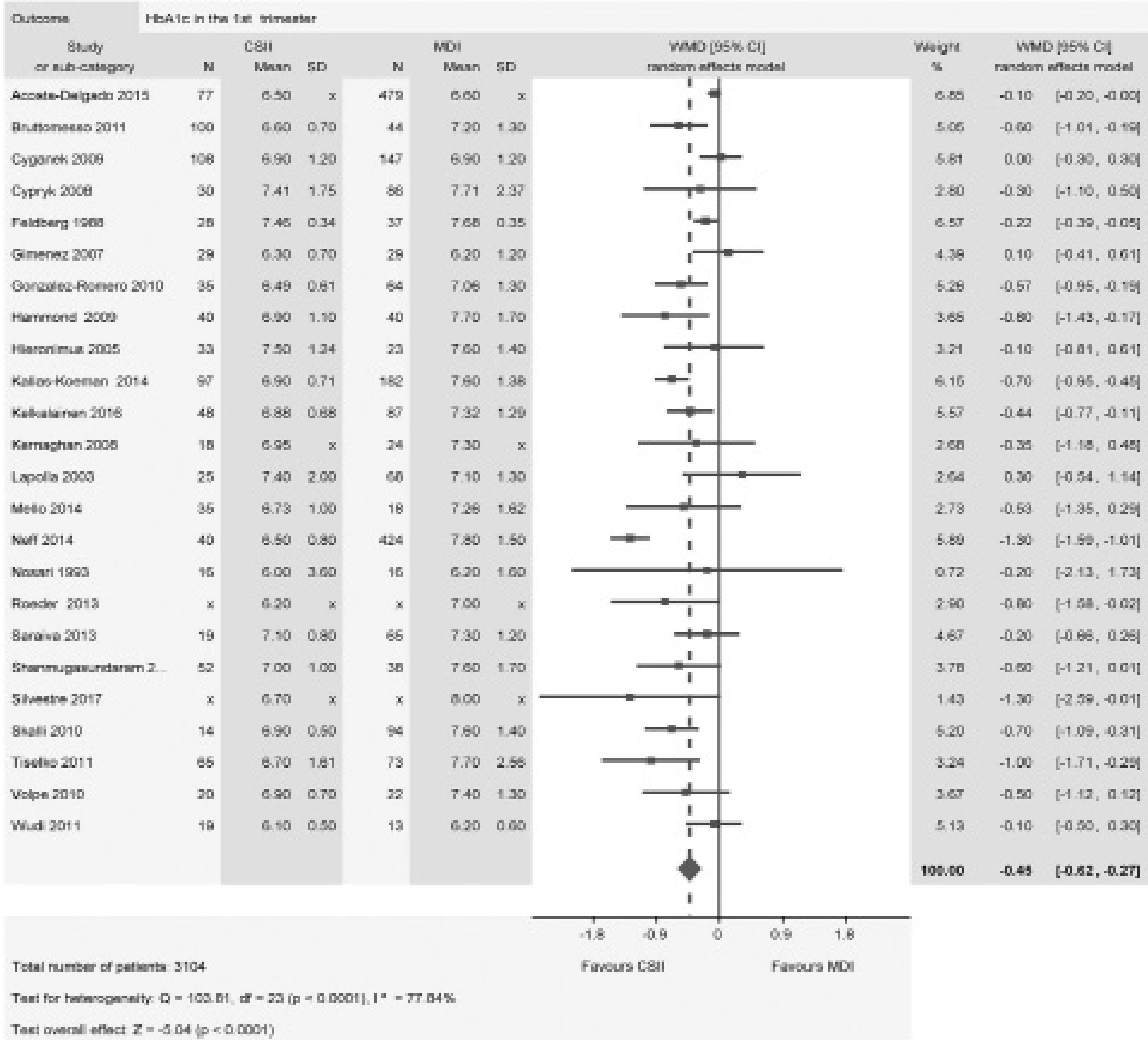

\section{Figure 1}

Forest plot of the meta-analysis for the first trimester HbA1c level in pregnant women with T1DM receiving CSII vs MDI therapy.

showed higher risk of birth weight above $4500 \mathrm{~g}$ in the CSII group than the MDI group (RR 2.51; 95\%CI 1.20, 5.21; Supplementary Fig. 14). On the other hand, the probability of infants being born SGA was lower in the CSII group than the MDI group (RR 0.66; 95\%CI 0.45, 0.97; Supplementary Fig. 15). No significant differences were found between both methods of insulin delivery with respect to other foetal complications, including neonatal hypoglycaemia (RR 1.12; 95\%CI 0.97, 1.28; Supplementary Fig. 16), hyperbilirubinemia (RR 1.00; 95\%CI 0.83, 1.19; Supplementary Fig. 17), shoulder dystocia (RR 1.15; 95\%CI 0.70, 1.89; Supplementary Fig. 18), respiratory complications (RR 0.90; 95\%CI 0.71, 1.13; Supplementary Fig. 19) and intensive care unit admission (RR 0.93; 95\%CI 0.80, 1.09; Supplementary Fig. 20).

\section{Sensitivity analysis}

A sensitivity analysis showed that, in most cases, differences between studies with respect to their design, type of publication, moment of CSII initiation and type of prandial insulin did not explain the heterogeneity observed in the meta-analysis, with 1 exception regarding the first trimester HbA1c level, described 


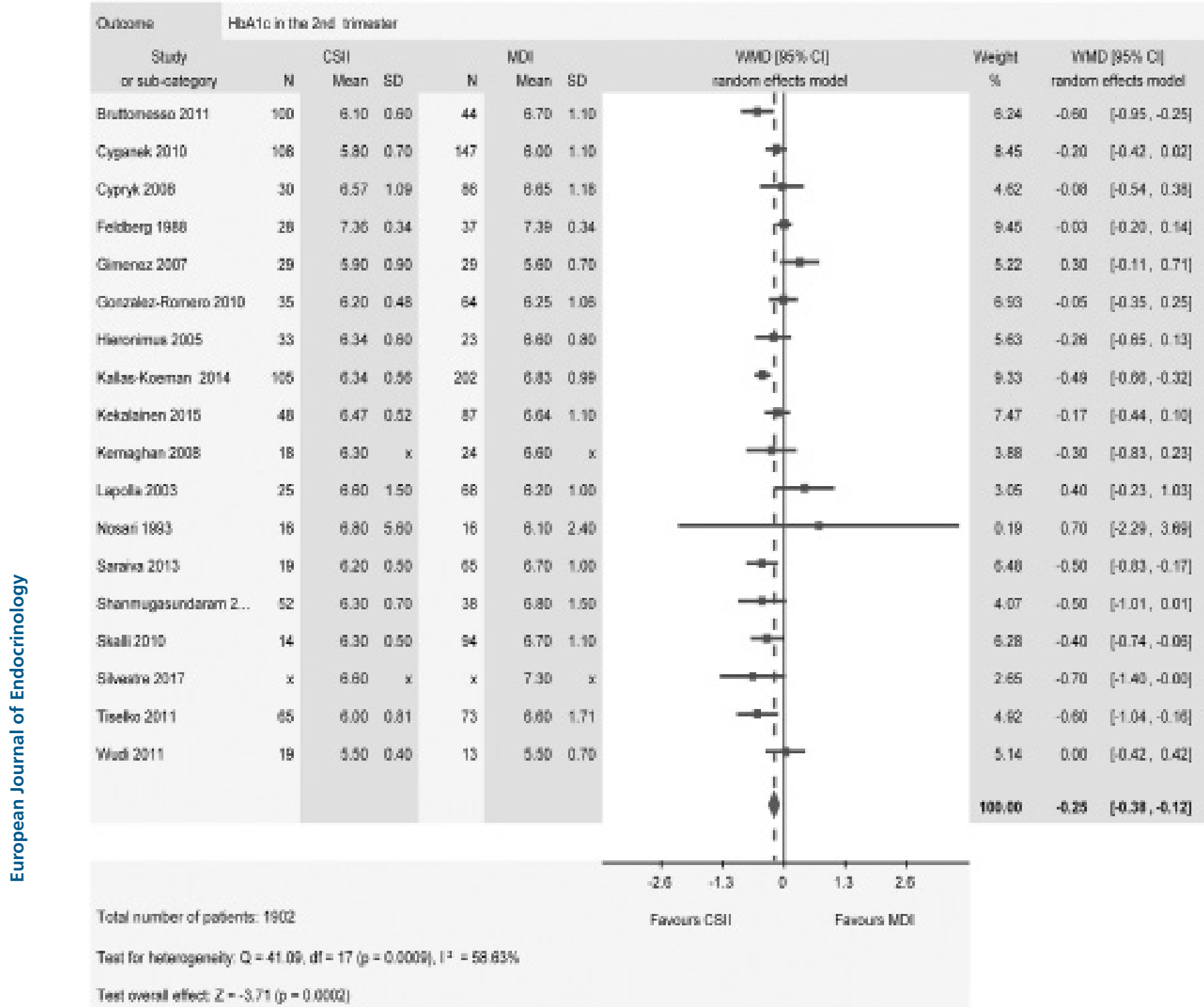

Figure 2

Forest plot of the meta-analysis for the second trimester $\mathrm{HbA1c}$ level in pregnant women with T1DM receiving CSII vs MDI therapy.

earlier. Additionally, a meta-analysis including only full-text papers resulted in a reduction of heterogeneity for 3 outcomes (preeclampsia, macrosomia and neonatal hypoglycaemia), but no interaction between abstracts and full-text papers was observed. We also intended to perform a subgroup analysis with respect to the preconception care; however, only 1 study (47) reported a subgroup analysis with respect to this variable, with the remaining papers reporting data collectively on women, regardless of whether they received preconception care.
As mentioned earlier, the sensitivity analysis did not reveal any interaction between RCTs and observational studies; however, it should be noted that only 4 RCTs with a small sample size were identified, while all remaining studies were of an observational design (including more than 7000 pregnancies in total). Therefore, a subgroup meta-analysis restricted to the observational studies revealed similar results to the base case scenario (involving both RCTs and non-RCTs), while the pooled data of RCTs did not show any difference between the studied groups for any of the analysed outcomes. 




Figure 3

Forest plot of the meta-analysis for the third trimester HbA1c level in pregnant women with T1DM receiving CSII vs MDI therapy.

\section{Assessing a risk of publication bias}

No sign of publication bias according to the Egger's test and the Begg-Mazumdar statistic was demonstrated towards the $\mathrm{HbA}_{1 \mathrm{c}}$ level, insulin dose in each trimester, risk of hypoglycaemia, risk of DKA, as well as most maternal and foetal complications, except for preeclampsia and preterm delivery. 


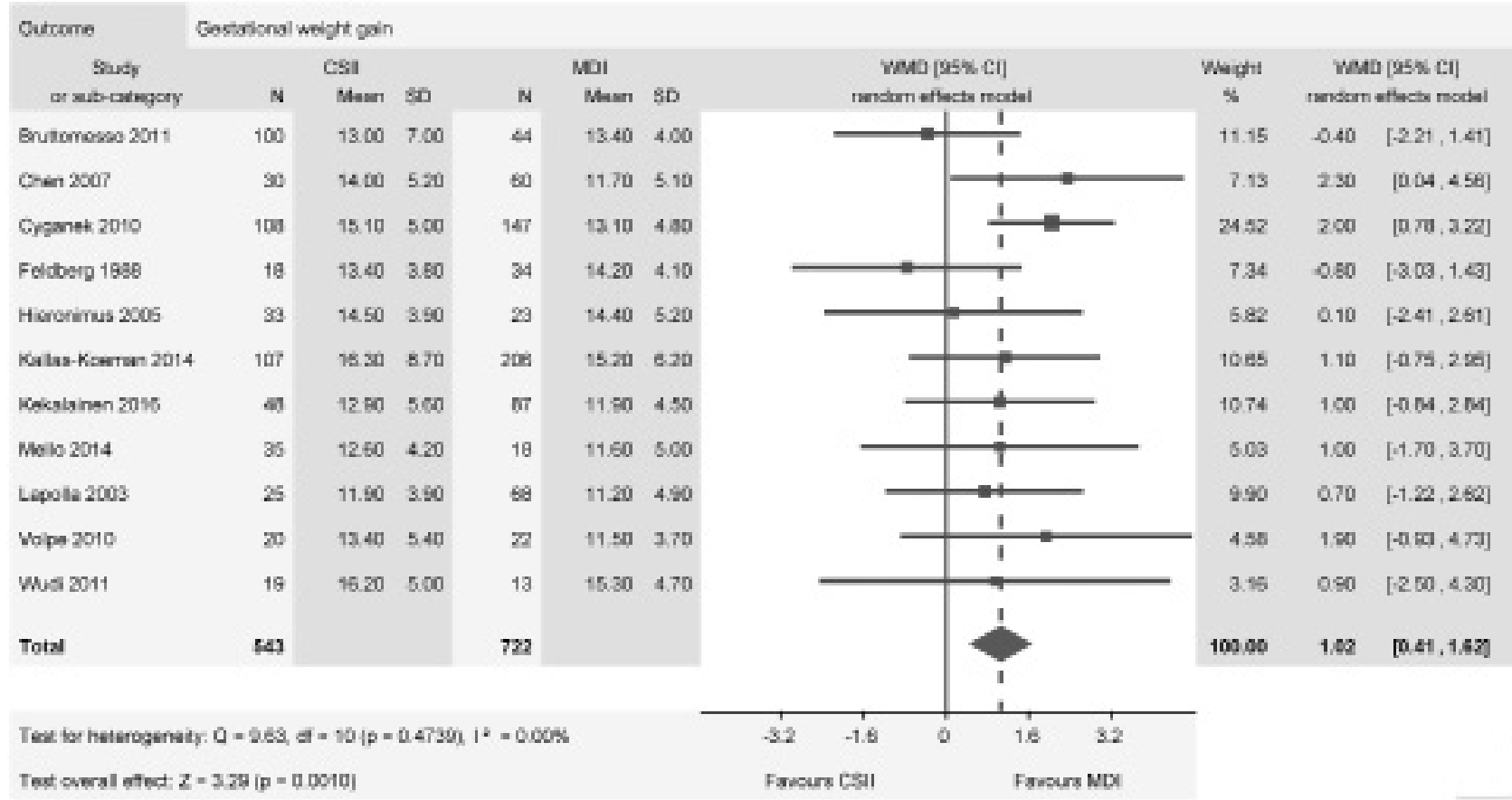

\section{Figure 4}

Forest plot of the meta-analysis for gestational weight gain in pregnant women with T1DM receiving CSII vs MDI therapy.

\section{Discussion}

\section{Main findings and comparison with existing literature}

This meta-analysis, based on a systematic review comparing CSII and MDI therapy in pregnant women with T1DM, included for the first time, all available studies on the subject, regardless of their methodology (RCT or observational study). These broad inclusion criteria allowed us to analyse 47 publications, encompassing 7824 pregnancies complicated by T1DM, far more than earlier meta-analyses restricted only to RCTs. Our pooled results of all eligible studies showed that the $\mathrm{HbA1c}$ level, the main glycaemic control outcome, was slightly lower in patients using insulin pumps than MDI therapy throughout the first and second trimester of pregnancy. We also identified a few other differences in clinical maternal or neonatal outcomes.

The largest difference in the HbA1c level occurred during the first trimester, where it was almost $0.5 \%$ lower in the CSII group compared to the MDI group, and then showed a narrower difference in subsequent trimesters. In the third trimester, the difference was not significant, at a magnitude of less than $0.1 \%$, without clinical relevance. A number of RCTs and several meta-analyses, as well as observational studies, have previously shown that CSII results in better glycaemic control than MDI in the general
T1DM population $(12,67,68,69,70)$. It is likely that the differences favouring CSII in the current report, particularly in the first trimester, reflect the fact that women on insulin pumps had lower glucose levels already outside of pregnancy in the preconception period $(69,70)$. This notion is further supported by our subgroup meta-analysis that showed a larger difference in first trimester HbA1c levels in relation to the MDI group in women who started pump therapy before pregnancy, compared to women who switched to CSII at the beginning of pregnancy.

Since the individual studies included in this metaanalysis provided rather scarce information regarding patients' characteristics and the details of the interventions, a meta-regression to determine any possible associated factors was not possible. However, available data suggest that preconception care, including pregnancy planning, might have influenced the final results. In most studies presenting detailed information, the percentage of women with preconception care was higher in the CSII group than in the MDI group, while in the remaining studies, a nonsignificant deviation favouring pump therapy was observed. It thus seems possible that the advantage of CSII over MDI therapy might, at least partially, originate from the group construction and patients' involvement in preconception care. It is indeed well-known that diabetes care during pregnancy planning is one of the most important factors 


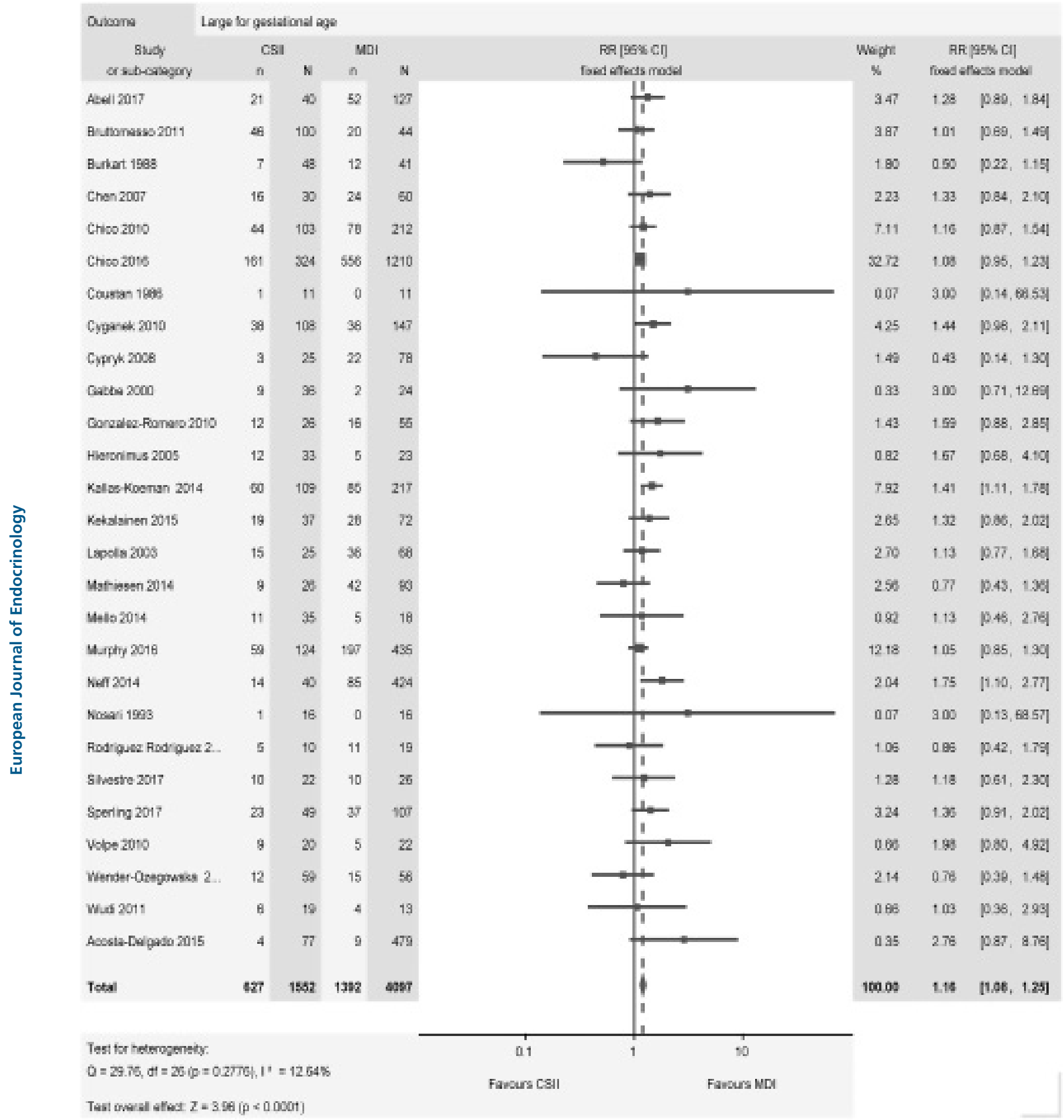

Figure 5

Forest plot of the meta-analysis for the risk of infants being born large-for-gestational-age to pregnant women with T1DM receiving CSII vs MDI therapy.

contributing to metabolic control and obstetrical outcomes in pregnant women with T1DM, and substantially affects the $\mathrm{HbA}_{1 \mathrm{c}}$ level in the first trimester (71).
In our meta-analysis, the difference in $\mathrm{HbA}_{1 \mathrm{c}}$ values between the two arms decreased in the second trimester, and finally disappeared in the last trimester. This may be 
explained by the fact that in the clinical setting, patients on MDI therapy often participate less frequently in preconception care and pregnancy planning, but then substantially increase their awareness of the importance of optimal glycaemic control for foetal well-being as their pregnancy progresses. Subsequently, some non-random factors, such as preconception care and pregnancy planning, become less important in later months. In our study, by the end of the pregnancy, the difference between CSII and MDI therapy vanished, suggesting that both methods of insulin delivery have equal potential to achieve a target $\mathrm{HbA}_{1 \mathrm{c}}$ value for pregnancy, especially when the patient is highly motivated, as is typical for expecting women. One may postulate that outside pregnancy, when the level of motivation is lower, CSII therapy is associated with a slightly higher effectiveness. Interestingly, it was shown in our earlier observational study that postpregnancy glycaemic control in women with T1DM was better in women on pumps, although it was still worse than that achieved during pregnancy (2). Furthermore, 1 study included in the meta-analysis reported that the $\mathrm{HbA}_{1 \mathrm{c}}$ level in the MDI group was even lower than that in the CSII arm at the end of pregnancy, although the inverse relationship was present at the beginning of the pregnancy (35).

Our meta-analysis revealed that in all 3 trimesters of pregnancy, the requirement for insulin was lower in the CSII group than in patients receiving MDI therapy. However, for unclear reasons, a high level of heterogeneity between the studies was observed. Nevertheless, the obtained results are in agreement with observations from the general population with T1DM, where pump therapy was associated with lower doses of insulin. For example, in a registry of the Slovenian population, switching from MDI to CSII therapy, led to reduction in the $\mathrm{HbA}_{1 \mathrm{c}}$ level and concomitant decrease in insulin requirements (70). Similar results were obtained in the prospective study on 153 patients with T1DM in whom MDI therapy was replaced by CSII, resulting in better glycaemic control and reduction of daily insulin requirements (68).

Our initial analysis did not find any difference between the two therapy modes in terms of GWG; however, some heterogeneity between the studies was observed. This was probably derived from one Spanish study reporting a higher GWG in MDI than in CSII (35), whereas the opposite tendency was observed in the remainder. In the Spanish study, the preconception $\mathrm{HbA}_{1 \mathrm{c}}$ level was higher in the MDI group than in the CSII group ( $7.6 \%$ vs $6.6 \%$ ), while a reverse tendency was noticed in the third trimester $(5.9 \%$ vs $6.2 \%)$. As a result, the reduction in $\mathrm{HbA}_{1 \mathrm{c}}$ levels during pregnancy was much larger in patients with T1DM on MDI therapy compared to CSII. Such a substantial $\mathrm{HbA}_{1 \mathrm{c}}$ level reduction was associated with a higher insulin dosage, which was clearly seen in the 12th gestational week $(0.70$ vs $0.51 \mathrm{U} / \mathrm{kg}$ ) and, at least in part, could have accounted for a higher GWG in the MDI arm. After excluding this study, a sensitivity analysis revealed a greater GWG in women with T1DM on pumps. This phenomenon might be explained by less stringent dietary habits during pump therapy, which could lead to a higher calorie intake and, thus, a larger pregnancy weight gain, as discussed in some individual studies $(2,72)$.

Another key outcome analysed in the current research was the number of hypoglycaemic episodes. The risk of hypoglycaemia in pregnant women with T1DM was previously reported to be $3-5$ times higher in the first trimester than in the preconception period (73). The meta-analysis performed in the general T1DM population showed that CSII therapy was associated with a 3-4 times lower rate of severe hypoglycaemia (12). Somewhat unexpectedly, we found in our metaanalysis that the percentage of women who experienced at least 1 severe hypoglycaemic episode was similar in both treatment groups. There are several possible explanations for this finding, such as the different target populations (pregnant women with T1DM vs the general population with T1DM) and the different therapeutic glycaemic aims. Additionally, pregnant women on MDI less frequently received preconception care and booked antenatal appointments later in their pregnancy; thus, some hypoglycaemic episodes might have been missed, especially as most occur in the first trimester $(71,73)$.

The pregnancy period in women with T1DM has been linked earlier with a higher risk of not only hypoglycaemia, but also the life-threatening condition of DKA (74). Earlier data from the general population suggested a higher frequency of DKA in T1DM patients on insulin pumps (75). This was explained by the specificity of delivery method (i.e. lack of subcutaneous depot) and type of insulin use (i.e. almost exclusively short-acting analogues rather than human insulin). Indeed, even a short-term pause in insulin delivery, if not quickly discovered and eliminated, might lead to a fast rise in glycaemia and DKA occurrence. However, more recent data did not confirm this finding in the general population with T1DM (68), which is likely attributed to the technological advancement of the pumps, as well as improved patient qualification for this type of therapy (76). Our meta-analysis indeed showed that the risk of DKA was not different between the groups. 
While the pooled results of 5 RCT studies published between 1986 and 1993 revealed a higher prevalence of DKA in women with T1DM on CSII therapy (7\%) than on MDI therapy (0\%), this difference was not statistically significant (16). In addition, observational studies published between 2010 and 2014 showed a similar risk of DKA in pregnant women with T1DM regardless of the insulin delivery method they used $(25,28,30,38)$. This seems to confirm the assumption that patient education and technological progress has reduced the risk of DKA during T1DM-complicated pregnancy observed earlier on pump therapy.

Our results suggest that insulin pump use was associated with an increased risk of infants being born LGA. This was observed in spite of the fact that the third trimester HbA1c level, a strong influential factor on the birth weight of infants born to mothers with T1DM, was almost identical in both study groups (77). One possible explanation is a higher GWG in women with T1DM on CSII therapy, since several recent reports presented an excess of maternal weight gain during pregnancy as a risk factor for neonatal macrosomia $(78,79)$. Additionally, it can be postulated that better glycaemic control in the first trimester might lead to a better functioning placenta later during pregnancy. This phenomenon may explain why there remains a high proportion of macrosomia reported in infants born to pregnant women with T1DM, in spite of improvement in glycaemic control that is observed in many studies $(77,80,81)$. This may also possibly explain a lower risk of infants being born SGA in the CSII therapy group in this meta-analysis. Finally, the finding of a higher risk of spontaneous abortion in women on CSII therapy compared to those on MDI therapy requires comment. It seems to be a finding very likely influenced by nonrandom factors, mainly the more frequent pregnancy planning in the pump group. As a result, women on CSII therapy tend to book their first pregnancy appointment earlier, which may result in more frequent recording of spontaneous miscarriages (82).

\section{Limitations}

Our study has some shortcomings that may potentially influence its results. Firstly, only a few RCTs were available, having been performed many years ago and having included a small number of women; therefore, the results of our meta-analysis are derived mainly from observational studies, which have their obvious limitations. Moreover, only 5 non-RCT publications controlled for confounding factors during the assignment process, and in most cases, data were analysed retrospectively. Therefore, the results of our meta-analysis reflect a therapeutic effect observed in the clinical setting, and the direct comparison between CSII and MDI therapy should be interpreted in the context of the methodological limitations of the available research data. Finally, we were able to include only very limited data on the most recent insulin pumps, particularly those that feature tools to integrate CSII and continuous glucose monitoring systems (CGMS), such as the low glucose suspend function, which is growing rapidly in use worldwide.

\section{Conclusions and implications}

In summary, the results of our systematic review and metaanalysis of RCTs and observational studies showed that in pregnancy complicated by T1DM, insulin pump therapy compared to MDI therapy resulted in better glycaemic control in the first trimester. However, this difference steeply decreased throughout pregnancy, probably due to its nonrandom origin, such as preconception care. CSII therapy was also associated with lower insulin requirements and larger weight gain in mothers, as well as an increased risk of infants being born LGA and decreased risk of being born SGA.

As both CSII and MDI therapy seem to exhibit similar potential in achieving glycaemic control in pregnant women with T1DM, the decision of choosing of either therapy should involve, among other factors, patient preferences, clinician experience, local clinical practice, as well as country-specific reimbursement policies. A special emphasis should be placed on the pregnancy planning, as well as education involving recommended diabetic diets and GWG, with the latter being particularly pertinent in patients on CSII therapy. Future studies will be needed to determine whether the newest generations of insulin pumps with integrated CGMS and elements of closed-loop monitoring systems will exhibit an advantage over the traditional MDI therapeutic approach for the management of pregnant women with T1DM.

Supplementary data

This is linked to the online version of the paper at https://doi.org/10.1530/ EJE-17-0804.

\section{Declaration of interest}

The authors declare that there is no conflict of interest that could be perceived as prejudicing the impartiality of this review. 
Funding

This work was supported by the National Science Centre grant (decision no. UMO-2013/11/D/NZ5/03219 to ALS).

\section{Author contribution statement}

P R, M T M: study design, protocol development; P R, A L S: searching medical databases; PR, A L S: data analysis; P R, A L S, K C, M T M: research data, data interpretation; P R, A L S, M T M: writing the manuscript; K C: critical review of the manuscript; $M T$ M: project coordination, final approval of the manuscript. M T M is the guarantor of the data and, as such, had full access to all the data in the study and takes responsibility for the integrity of the data and the accuracy of the data analysis.

\section{Acknowledgment}

The authors thank Claudia Frankfurter, University of Toronto, Faculty of Medicine, for linguistic review of the manuscript.

\section{References}

1 Bell R, Bailey K, Cresswell T, Hawthorne G, Critchley J, LewisBarned N \& Northern Diabetic Pregnancy Survey Steering Group. Trends in prevalence and outcomes of pregnancy in women with pre-existing type I and type II diabetes. BJOG: An International Journal of Obstetrics and Gynaecology 2008115 445-452. (https://doi. org/10.1111/j.1471-0528.2007.01644.x)

2 Cyganek K, Hebda-Szydlo A, Skupien J, Katra B, Janas I, Borodako A, Kaim I, Klupa T, Reron A \& Malecki MT. Glycemic control and pregnancy outcomes in women with type 2 diabetes from Poland. The impact of pregnancy planning and a comparison with type 1 diabetes subjects. Endocrine 201140 243-249. (https://doi. org/10.1007/s12020-011-9475-0)

3 Fong A, Serra A, Herrero T, Pan D \& Ogunyemi D. Pre-gestational versus gestational diabetes: a population based study on clinical and demographic differences. Journal of Diabetes and its Complications 201428 29-34. (https://doi.org/10.1016/j.jdiacomp.2013.08.009)

4 de Andrés AL, Jiménez-García R \& Carrasco-Garrido P. Trends in pregestational diabetes among women delivering in Spain, 2001-2008. International Journal of Gynecology and Obstetrics 2012117 182-183. (https://doi.org/10.1016/j.ijgo.2011.12.006)

5 Mayer-Davis EJ, Lawrence JM, Dabelea D \& Wagenknecht L. Incidence trends of type 1 and type 2 diabetes among youths, 2002-2012. New England Journal of Medicine 2017376 1419-1429. (https://doi.org/10.1056/NEJMoa1610187)

6 Colstrup M, Mathiesen ER, Damm P, Jensen DM \& Ringholm L. Pregnancy in women with type 1 diabetes: have the goals of St. Vincent declaration been met concerning foetal and neonatal complications? Journal of Maternal-Fetal and Neonatal Medicine 2013 26 1682-1686. (https://doi.org/10.3109/14767058.2013.794214)

7 Rosenn B, Miodovnik M, Combs CA, Khoury J \& Siddiqi TA. Glycemic thresholds for spontaneous abortion and congenital malformations in insulin-dependent diabetes mellitus. Obstetrics and Gynecology 199484 515-520.

8 Nielsen GL, Møller M \& Sørensen HT. HbA1c in early diabetic pregnancy and pregnancy outcomes: a Danish population-based cohort study of 573 pregnancies in women with type 1 diabetes. Diabetes Care 200629 2612-2616. (https://doi.org/10.2337/dc060914)

9 Temple RC, Aldridge VJ \& Murphy HR. Prepregnancy care and pregnancy outcomes in women with type 1 diabetes. Diabetes Care 200629 1744-1749. (https://doi.org/10.2337/dc05-2265)
10 Temple R, Aldridge V, Greenwood R, Heyburn P, Sampson M $\&$ Stanley K. Association between outcome of pregnancy and glycaemic control in early pregnancy in type 1 diabetes: population based study. BMJ 2002325 1275-1276. (https://doi.org/10.1136/ bmj.325.7375.1275)

11 Atkinson MA, Eisenbarth GS \& Michels AW. Type 1 diabetes. Lancet 2014383 69-82. (https://doi.org/10.1016/S01406736(13)60591-7)

12 Pickup JC \& Sutton AJ. Severe hypoglycaemia and glycaemic control in Type1 diabetes: meta-analysis of multiple daily insulin injections compared with continuous subcutaneous insulin infusion. Diabetic Medicine 200825 765-774. (https://doi.org/10.1111/j.14645491.2008.02486.x)

13 Burkart W, Hanker JP \& Schneider HP. Complications and fetal outcome in diabetic pregnancy. Intensified conventional versus insulin pump therapy. Gynecologic and Obstetric Investigation 198826 104-112. (https://doi.org/10.1159/000293680)

14 Coustan DR, Reece EA, Sherwin RS, Rudolf MC, Bates SE, Sockin SM, Holford T \& Tamborlane WV. A randomized clinical trial of the insulin pump vs intensive conventional therapy in diabetic pregnancies. JAMA 1986255 631-636. (https://doi.org/10.1001/ jama.1986.03370050073024)

15 Laatikainen L, Teramo K, Hieta-Heikurainen H, Koivisto V \& Pelkonen R. A controlled study of the influence of continuous subcutaneous insulin infusion treatment on diabetic retinopathy during pregnancy. Acta Medica Scandinavica 1987221 367-376. (https://doi.org/10.1111/j.0954-6820.1987.tb03358.x)

16 Mukhopadhyay A, Farrell T, Fraser RB \& Ola B. Continuous subcutaneous insulin infusion vs intensive conventional insulin therapy in pregnant diabetic women: a systematic review and metaanalysis of randomized, controlled trials. American Journal of Obstetrics and Gynecology 2007197 447-456. (https://doi. org/10.1016/j.ajog.2007.03.062)

17 Farrar D, Tuffnell DJ, West J \& West HM. Continuous subcutaneous insulin infusion versus multiple daily injections of insulin for pregnant women with diabetes. Cochrane Database of Systematic Reviews 2016 CD005542. (https://doi.org/10.1002/14651858. CD005542.pub3)

18 Jadad AR, Moore RA, Carroll D, Jenkinson C, Reynolds DJ, Gavaghan DJ \& McQuay HJ. Assessing the quality of reports of randomized clinical trials: is blinding necessary? Controlled Clinical Trials 199617 1-12. (https://doi.org/10.1016/0197-2456(95)00134-4)

19 Wells GA, Shea B, O'Connell D, Peterson J, Welch V, Losos M \& Tugwell P. The Newcastle-Ottawa Scale (NOS) for assessing the quality of nonrandomised studies in meta-analyses. (available at: http://www.ohri.ca/programs/clinical_epidemiology/oxford.asp)

20 Begg CB \& Mazumdar M. Operating characteristics of a rank correlation test for publication bias. Biometrics 199450 1088-1101. (https://doi.org/10.2307/2533446)

21 Duval S \& Tweedie R. Trim and fill: a simple funnel-plot-based method of testing and adjusting for publication bias in metaanalysis. Biometrics 200056 455-463. (https://doi.org/10.1111/ j.0006-341X.2000.00455.x)

22 Duval S \& Tweedie R. A nonparametric 'trim and fill' method of accounting for publication bias in meta-analysis. Journal of the American Statistical Association 200095 89-98. (https://doi.org/10.10 80/01621459.2000.10473905)

23 Abell SK, Suen M, Pease A, Boyle JA, Soldatos G, Regan J, Wallace EM $\&$ Teede HJ. Pregnancy outcomes and insulin requirements in women with type 1 diabetes treated with continuous subcutaneous insulin infusion and multiple daily injections: cohort study. Diabetes Technology and Therapeutics 201719 280-287. (https://doi. org/10.1089/dia.2016.0412)

24 Acosta Delgado D, Martinez Ortega AJ, Moreno Reina E \& Cerrillos González L. Continuous subcutaneous insulin infusion: better metabolic control than multi-dose insulin, but similar obstetrics 
outcomes in pregestational diabetes mellitus type 1. Diabetes 201564 A278. (https://doi.org/doi.org/10.2337/db159321471)

25 Bruttomesso D, Bonomo M, Costa S, Dal Pos M, Di Cianni G, Pellicano F, Vitacolonna E, Dodesini AR, Tonutti L, Lapolla A et al. Type 1 diabetes control and pregnancy outcomes in women treated with continuous subcutaneous insulin infusion (CSII) or with insulin glargine and multiple daily injections of rapid-acting insulin analogues (glargine-MDI). Diabetes and Metabolism 201137 426-431. (https://doi.org/10.1016/j.diabet.2011.02.002)

26 Chen R, Ben-Haroush A, Weissmann-Brenner A, Melamed N, Hod M \& Yogev Y. Level of glycemic control and pregnancy outcome in type 1 diabetes: a comparison between multiple daily insulin injections and continuous subcutaneous insulin infusions. American Journal of Obstetrics and Gynecology 2007197 404.e1-404.e5. (https://doi. org/10.1016/j.ajog.2007.06.007)

27 Cheng Y, Block-Kurbisch I, Inturrisi M, Ustinov A \& Caughey A. Insulin pump compared to injected insulin in pregnant women with type 1 diabetes. American Journal of Obstetrics and Gynecology 2006 195 S125. (https://doi.org/10.1016/j.ajog.2006.10.425)

28 Chico A, Saigi I, García-Patterson A, Santos MD, Adelantado JM, Ginovart G, de Leiva A \& Corcoy R. Glycemic control and perinatal outcomes of pregnancies complicated by type 1 diabetes: influence of continuous subcutaneous insulin infusion and lispro insulin. Diabetes Technology and Therapeutics 201012 937-945. (https://doi. org/10.1089/dia.2010.0111)

29 Chico A, Herranz L, Corcoy R, Ramírez O, Goya MM, Bellart J, González-Romero S, Codina M, Sánchez P, Cortázar A et al. Glycemic control and maternal and fetal outcomes in pregnant women with type 1 diabetes according to the type of basal insulin. European Journal of Obstetrics and Gynecology and Reproductive Biology 2016206 84-91. (https://doi.org/10.1016/j.ejogrb.2016.07.490)

30 Cyganek K, Hebda-Szydlo A, Katra B, Skupien J, Klupa T, Janas I, Kaim I, Sieradzki J, Reron A \& Malecki MT. Glycemic control and selected pregnancy outcomes in type 1 diabetes women on continuous subcutaneous insulin infusion and multiple daily injections: the significance of pregnancy planning. Diabetes Technology and Therapeutics 201012 41-47. (https://doi.org/10.1089/ dia.2009.0081)

31 Cypryk K, Kosiński M, Kamińska P, Kozdraj T \& Lewiński A. Diabetes control and pregnancy outcomes in women with type 1 diabetes treated during pregnancy with continuous subcutaneous insulin infusion or multiple daily insulin injections. Polskie Archiwum Medycyny Wewnetrznej 2008118 339-344.

32 Feldberg D, Dicker D, Samuel N, Peleg D, Karp M \& Goldman JA. Intrapartum management of insulin-dependent diabetes mellitus (IDDM) gestants. A comparative study of constant intravenous insulin infusion and continuous subcutaneous insulin infusion pump (CSIIP). Acta Obstetricia et Gynecologica Scandinavica 198867 333-338. (https://doi.org/10.1111/j.1600-0412.1988.tb07810.x)

33 Gabbe SG, Holing E, Temple P \& Brown ZA. Benefits, risks, costs, and patient satisfaction associated with insulin pump therapy for the pregnancy complicated by type 1 diabetes mellitus. American Journal of Obstetrics and Gynecology 2000182 1283-1291. (https://doi. org/10.1067/mob.2000.106182)

34 Giménez M, Conget I, Nicolau J, Pericot A \& Levy I. Outcome of pregnancy in women with type 1 diabetes intensively treated with continuous subcutaneous insulin infusion or conventional therapy. A case-control study. Acta Diabetologica 200744 34-37. (https://doi. org/10.1007/s00592-007-0239-5)

35 González-Romero S, González-Molero I, Fernández-Abellán M, Domínguez-López ME, Ruiz-de-Adana S, Olveira G \& Soriguer F. Continuous subcutaneous insulin infusion versus multiple daily injections in pregnant women with type 1 diabetes. Diabetes Technology and Therapeutics 201012 263-269. (https://doi. org/10.1089/dia.2009.0140)
36 Hammond P, Ray S, Carling J, Dudley S, Dinning L, Johnson K \& Macdonald A. Is CSII therapy more effective than MDI therapy in achieving target HbAlc levels in pregnant women with type 1 diabetes? Diabetic Medicine Conf Diabetes UKs Annu Prof Conf 2009 Glasg U K Conf Start 20090311 Conf End 20090313 Conf Publ 2009 2630.

37 Hiéronimus S, Cupelli C, Bongain A \& Fenichel P. Grossesse et diabète de type 1 : pompe à insuline versus traitement intensifié conventionnel. Gynécologie Obstétrique \& Fertilité 200533 389-394. (https://doi.org/10.1016/j.gyobfe.2005.04.020)

38 Kallas-Koeman MM, Kong JM, Klinke JA, Butalia S, Lodha AK, Lim KI, Duan QM \& Donovan LE. Insulin pump use in pregnancy is associated with lower HbA1c without increasing the rate of severe hypoglycaemia or diabetic ketoacidosis in women with type 1 diabetes. Diabetologia 201457 681-689. (https://doi.org/10.1007/ s00125-014-3163-6)

39 Kekäläinen P, Juuti M, Walle T \& Laatikainen T. Continuous subcutaneous insulin infusion during pregnancy in women with complicated type 1 diabetes is associated with better glycemic control but not with improvement in pregnancy outcomes. Diabetes Technology and Therapeutics 201618 144-150. (https://doi. org/10.1089/dia.2015.0165)

40 Kernaghan D, Farrell T, Hammond P \& Owen P. Fetal growth in women managed with insulin pump therapy compared to conventional insulin. European Journal of Obstetrics and Gynecology and Reproductive Biology 2008137 47-49. (https://doi.org/10.1016/j. ejogrb.2007.05.006)

41 Lapolla A, Dalfrà MG, Masin M, Bruttomesso D, Piva I, Crepaldi C, Tortul C, Dalla Barba B \& Fedele D. Analysis of outcome of pregnancy in type 1 diabetics treated with insulin pump or conventional insulin therapy. Acta Diabetologica 200340 143-149. (https://doi.org/10.1007/s00592-003-0103-1)

42 Lewis-Jenkins J, Tagoury G, Beaverstock J, Lloyd A, Littlewood E \& Evans P. A study comparing continuous subcutaneous insulin infusion therapy with multiple daily injections in pregnant women with Type 1 diabetes. Diabetic Medicine Conf Diabetes UK Annu Prof Conf 2011 Lond U K Conf Start 20110330 Conf End 20110401 Conf Publ 201128169

43 Lorenzini F, Lorenzini F, Guyard Boileau B, Melki V \& Hanaire H. Insulin pump is effective to reduce macrosomia in pregnancies complicated by type 1 diabetes. Diabetology Conf 48th Annu Meet Eur Assoc Study Diabetes EASD 2012 Berl Ger Conf Start 20121001 Conf End 20121005 Conf Publ 201255438.

44 Mathiesen JM, Secher AL, Ringholm L, Nørgaard K, Hommel E, Andersen HU, Damm P \& Mathiesen ER. Changes in basal rates and bolus calculator settings in insulin pumps during pregnancy in women with type 1 diabetes. Journal of Maternal-Fetal and Neonatal Medicine 201427 724-728. (https://doi.org/10.3109/14767058.2013.837444)

45 Mello G, Biagioni S, Ottanelli S, Nardini C, Tredici Z, Serena C, Marchi L \& Mecacci F. Continuous subcutaneous insulin infusion (CSII) versus multiple daily injections (MDI) of rapid-acting insulin analogues and detemir in type 1 diabetic (T1D) pregnant women. Journal of Maternal-Fetal and Neonatal Medicine 201528 276-280. (https://doi.org/10.3109/14767058.2014.914922)

46 Murphy HR, Curnow P, Cartright C, Bell R, Maresh M \& LewisBarned N. Pens or pumps for optimal glycaemic control during pregnancy: an analysis of 598 Type 1 diabetes pregnancies from the 2013 National Pregnancy in Diabetes audit. Diabetic Medicine 2016 33 168. (https://doi.org/10.1111/dme.46_13048)

47 Neff KJ, Forde R, Gavin C, Byrne MM, Firth RG, Daly S, McAuliffe FM, Foley M, Coffey M, Coulter-Smith S et al. Prepregnancy care and pregnancy outcomes in type 1 diabetes mellitus: a comparison of continuous subcutaneous insulin infusion and multiple daily injection therapy. Irish Journal of Medical Science 2014 183 397-403. (https://doi.org/10.1007/s11845-013-1027-6) 
48 Nosari I Nosari I, Maglio M.L, Lepore G, Cortinovis F \& Pagani G. 'Is continuous subcutaneous insulin infusion more effective than intensive conventional insulin therapy in the treatment of pregnant diabetic women?' Nosa. Diabetes, Nutrition and Metabolism, Clinical and Experimental 19936 33-37.

49 Quirós C, Patrascioiu I, Perea V, Bellart J, Conget I \& Vinagre I. Postpartum metabolic control in a cohort of women with type 1 diabetes. Endocrinologia Y Nutricion 201562 125-129. (https://doi. org/10.1016/j.endonu.2014.11.003)

50 Rodriguez Rodriguez F, Ramirez Garcia O, Del Otero Sanz L, Lopez A A \& Angel Garcia Hernandez J. Continuous insulin infusion versus multiple daily injections in pregnant with type 1 diabetes. Journal of Maternal-Fetal and Neonatal Medicine Conf 22nd Eur Congr Perinat Med 2010 Granada Spain Conf Start 20100526 Conf End 20100529 Conf Publ 201023539.

51 Roeder H, Moore T \& Ramos G. The incidence of hypoglycemic episodes in pregnant women with type 1 diabetes using insulin injections versus insulin pump. American Journal of Obstetrics and Gynecology Conf 33rd Annu Meet Soc Matern -Fetal Med Pregnancy Meet San Franc CA U S 2013208 (suppl 1) S119. (https://doi. org/10.1016/j.ajog.2012.10.425)

52 Salmeen K, Block-Kurbisch I, Zink F, Shafer S \& Cheng Y. Pregnancy outcomes among women with type 1 diabetes managed with continuous insulin pumps versus multiple injections: a propensityscore based analysis. American Journal of Obstetrics and Gynecology Conf 33rd Annu Meet Soc Matern-Fetal Med Pregnancy Meet San Franc CA U S 2013208 (Suppl 1) S124. (https://doi.org/10.1016/j. ajog.2012.10.437)

53 Samoylova J, Oleynik O \& Novoselova M The role of pump therapy in pregnant women with type 1 diabetes and its impact on development of fetopathy. Hormone Research in Paediatrics Conf 9th Jt Meet Paediatr Endocrinol ESPE - PES - APEG - APPES - ASPAE - JSPE - SLEP Milan Italy Conf Start 20130919 Conf End 20130922 Conf Publ 2013 278. (https://doi.org/10.1159/000354131)

54 Sampanis C, Mouslech Z, Zografou I, Kartali N, Tsiotsiou E \& Zamboulis C. Continuous subcutaneous insulin infusion versus multiple daily injection therapy in pregnant women with type 1 diabetes. Diabetes Technology and Therapeutics Conf 4th Int Conf Adv Technol Treat Diabetes ATTD 2011 Lond U K Conf Start 20110216 Conf End 20110219 Conf Publ 201113 268. (https://doi. org/10.1089/dia.2010.1219)

55 Saraiva J, Paiva S, Ruas L, Barros L, Baptista C, Melo M, Alves M, Gouveia S, Moreno C, Guelho D, et al. Type 1 diabetes and pregnancy: continuous subcutaneous insulin infusion systems versus multiple daily injection therapy. Diabetology Conf 49th Annu Meet Eur Assoc Study Diabetes EASD 2013 Barc Spain Conf Start 20130923 Conf End 20130927 Conf Publ 201356 505-506. (https://doi. org/10.1007/s00125-013-3012-z)

56 Sargent J, Roeder H, Ward K, Moore TR \& Ramos GA. Continuous subcutaneous insulin infusion versus multiple daily injections of insulin for the management of type 1 diabetes mellitus in pregnancy: association with neonatal chemical hypoglycemia. American Journal of Perinatology 201532 1324-1330. (https://doi. org/10.1055/s-0035-1564426)

57 Shanmugasundaram M, Rogers H, Marks P, Jain A, Marsh M.S, Gayle C, Amiel S A \& Choudhary P. Conversion of pregnant patients with type 1 diabetes from multiple injection therapy to continuous subcutaneous insulin infusion in early pregnancy is safe and efficacious. Diabetology Conf 46th Annu Meet Eur Assoc Study Diabetes EASD 2010 Stockh Swed Conf Start 20100920 Conf End 20100924 Conf Publ 201053 433. (htps://doi.org/10.1007/s00125. 010-1872-z)

58 Silvestre C, Gomes A, Carvalho MR Gomes A, Carvalho MR, Wessling A, Pinto L \& Bugalho MJ. Type 1 diabetes treated with insulin pump or conventional insulin therapy in pregnancy: tertiary hospital outcomes. Diabetologia 201760 436-437. (https://doi. org/10.1007/s00125-017-4350-z)

59 Skalli S, Ferreira E, Morin C, Touzin K, Rey E \& Michon N. Continuous subcutaneous insulin infusion versus multiple daily injections of insulin in pregnant women with type 1 diabetes. ADA 2010 70th Sci Sess.

60 Smith CBJ, Rogers H, Gayle C, Jain A, Marsh M \& Amiel SA. Maternal and neonatal outcomes in women with type 1 diabetes: seven years of data from a retrospective analysis. BJOG: An International Journal of Obstetrics and Gynaecology Conf RCOG World Congr 2013 Liverp U K Conf Start 20130624 Conf End 20130626 Conf Publ 2013120112 (https://doi.org/10.1111/1471-0528.12293)

61 Sperling J, Maggio L, Has P, Daley J, Coustan DR \& Werner EF. Insulin delivery method and admission for glycemic control in pregnant women with type 1 diabetes mellitus. American Journal of Perinatology 2017. (https://doi.org/10.1055/s-0037-1604196)

62 Talaviya PA, Saboo BD, Joshi SR, Padhiyar JN, Chandarana HK, Shah SJ, Vyas CK \& Shah AN. Pregnancy outcome and glycemic control in women with type 1 diabetes: a retrospective comparison between CSII and MDI treatment. Diabetes and Metabolic Syndrome: Clinical Research and Reviews 20137 68-71. (https://doi. org/10.1016/j.dsx.2013.02.032)

63 Tiselko A, Borovik N \& Volgina O. Diabetes mellitus (DM) and reproductive system of woman. Geburtshilfe Und Frauenheilkunde 2011 71. (https://doi.org/10.1055/s-0031-1292734)

64 Volpe L, Pancani F, Aragona M, Lencioni C, Battini L, Ghio A, Resi V, Bertolotto A, Del Prato S \& Di Cianni G. Continuous subcutaneous insulin infusion and multiple dose insulin injections in type 1 diabetic pregnant women: a case-control study. Gynecological Endocrinology 201026 193-196. (https://doi.org/10.3109/09513590903215540)

65 Wender-Ozegowska E, Zawiejska A, Ozegowska K, WroblewskaSeniuk K, Iciek R, Mantaj U, Olejniczak D \& Brazert J. Multiple daily injections of insulin versus continuous subcutaneous insulin infusion for pregnant women with type 1 diabetes. Australian and New Zealand Journal of Obstetrics and Gynaecology 201353 130-135. (https://doi.org/10.1111/ajo.12027)

66 Wudi K Madarasz E, Nadasdi A, Turi Z, Magenheim R, Zsirai L, Csakany GM \& Kerenyi Z. Comparison of continuous subcutaneous insulin infusion and multiple daily insulin injections during pregnancy complicated by type 1 diabetes mellitus. Diabetes Technology and Therapeutics Conf 4th Int Conf Adv Technol Treat Diabetes ATTD 2011 Lond U K Conf Start 20110216 Conf End 20110219 Conf Publ 201113 236-237. (https://doi.org/10.1089/ dia.2010.1219)

67 Jeitler K, Horvath K, Berghold A, Gratzer TW, Neeser K, Pieber TR $\&$ Siebenhofer A. Continuous subcutaneous insulin infusion versus multiple daily insulin injections in patients with diabetes mellitus: systematic review and meta-analysis. Diabetologia 200851 941-951. (https://doi.org/10.1007/s00125-008-0974-3)

68 Giménez M, Conget I, Jansà M, Vidal M, Chiganer G \& Levy I. Efficacy of continuous subcutaneous insulin infusion in Type 1 diabetes: a 2-year perspective using the established criteria for funding from a National Health Service. Diabetic Medicine 200724 1419-1423. (https://doi.org/10.1111/j.1464-5491.2007.02287.x)

69 Jankovec Z, Hahn M, Grunder S, Lacigova S, Cechurova D, Krcma M, Zourek M, Haladova I \& Rusavy Z. Analysis of continuous patient data from the Czech National Register of patients with type 1 and type 2 diabetes using insulin pump therapy. Diabetes Research and Clinical Practice 201087 219-223. (https://doi.org/10.1016/j. diabres.2009.09.028)

70 Janez A. Continuous subcutaneous insulin infusion in adult type 1 diabetes mellitus: data from a registry at the University Medical Centre Ljubljana, Slovenia. Journal of International Medical Research 201240 1546-1551. (https://doi. org/10.1177/147323001204000434) 
71 Wahabi HA, Alzeidan RA, Bawazeer GA, Alansari LA \& Esmaeil SA Preconception care for diabetic women for improving maternal and fetal outcomes: a systematic review and meta-analysis. BMC Pregnancy Childbirth 201010 63. (https://doi.org/10.1186/14712393-10-63)

72 Bismuth E, Bouche C, Caliman C, Lepercq J, Lubin V, Rouge D, Timsit J, Vambergue A \& French-Speaking Diabetes Society. Management of pregnancy in women with type 1 diabetes mellitus: guidelines of the French-Speaking Diabetes Society (Société francophone du diabète [SFD]). Diabetes and Metabolism 201238 205-216. (https://doi.org/10.1016/j.diabet.2012.02.010)

73 Ringholm L, Pedersen-Bjergaard U, Thorsteinsson B, Damm P \& Mathiesen ER. Hypoglycaemia during pregnancy in women with Type 1 diabetes: hypoglycaemia during pregnancy in women with Type 1 diabetes. Diabetic Medicine 201229 558-566. (https://doi. org/10.1111/j.1464-5491.2012.03604.x)

74 Guo R-X, Yang L-Z, Li L-X \& Zhao X-P. Diabetic ketoacidosis in pregnancy tends to occur at lower blood glucose levels: case-control study and a case report of euglycemic diabetic ketoacidosis in pregnancy: DKA in pregnancy. Journal of Obstetrics and Gynaecology Research 200834 324-330. (https://doi.org/10.1111/j.14470756.2008.00720.x)

75 Mecklenburg RS, Benson EA, Benson JW, Fredlund PN, Guinn T, Metz RJ, Nielsen RL \& Sanner CA. Acute complications associated with insulin infusion pump therapy. Report of experience with 161 patients. JAMA 1984252 3265-3269. (https://doi.org/10.1001/ jama.252.23.3265)

76 Guilhem I, Leguerrier AM, Lecordier F, Poirier JY \& Maugendre D. Technical risks with subcutaneous insulin infusion. Diabetes and Metabolism 200632 279-284. (https://doi.org/10.1016/S12623636(07)70281-1)

77 Cyganek K, Skupien J, Katra B, Hebda-Szydlo A, Janas I, Trznadel-Morawska I, Witek P, Kozek E \& Malecki MT. Risk of macrosomia remains glucose-dependent in a cohort of women with pregestational type 1 diabetes and good glycemic control. Endocrine 201755 447-455. (https://doi.org/10.1007/s12020-0161134-z)

78 Egan AM, Dennedy MC, Al-Ramli W, Heerey A, Avalos G \& Dunne F. ATLANTIC-DIP: excessive gestational weight gain and pregnancy outcomes in women with gestational or pregestational diabetes mellitus. Journal of Clinical Endocrinology and Metabolism 201499 212-219. (https://doi.org/10.1210/ jc.2013-2684)

79 Alberico S, Montico M, Barresi V, Monasta L, Businelli C, Soini V, Erenbourg A, Ronfani L, Maso G \& Multicentre Study Group on Mode of Delivery in Friuli Venezia Giulia. The role of gestational diabetes, pre-pregnancy body mass index and gestational weight gain on the risk of newborn macrosomia: results from a prospective multicentre study. BMC Pregnancy Childbirth 201414 23. (https://doi.org/10.1186/14712393-14-23)

80 Kuc S, Wortelboer E, Koster M, de Valk HW, Schielen PC \& Visser GH. Prediction of macrosomia at birth in type- 1 and 2 diabetic pregnancies with biomarkers of early placentation: prediction of macrosomia in diabetic pregnancies. BJOG: An International Journal of Obstetrics and Gynaecology 2011118 748-754. (https://doi. org/10.1111/j.1471-0528.2011.02904.x)

81 Evers IM, de Valk HW, Mol BW, ter Braak EW \& Visser GH. Macrosomia despite good glycaemic control in Type I diabetic pregnancy; results of a nationwide study in The Netherlands. Diabetologia $2002 \mathbf{4 5}$ 1484-1489. (https://doi.org/10.1007/s00125-002-0958-7)

82 Cyganek K, Katra B, Hebda-Szydło A, Janas I, Trznadel-Morawska I, Witek P, Kozek E, Hohendorff J, Skupień J, Matejko B et al. Changes in preconception treatment and glycemic control in women with type 1 diabetes mellitus - a 15 year long single centre observation. Polish Archives of Internal Medicine 2016126 739-745. (https://doi. org/10.20452/pamw.3543)

Received 30 September 2017

Revised version received 5 February 2018

Accepted 13 March 2018 